\title{
Reductive Activation of Potential Antitumor Bis(aziridinyl)benzoquinones by Xanthine Oxidase: Competition between Oxygen Reduction and Quinone Reduction
}

\author{
K. J. Lusthof, ${ }^{*}$ W. Richter, ${ }^{*}$ N. J. de Mol, ${ }^{* 1}$ L. H. M. Janssen, ${ }^{*}$ W. Verboom, $†$ and D. N. Reinhoudt $\dagger$ \\ ${ }^{*}$ Deparlment of Pharmaceutical Chemistry, Facully of Pharmacy, Universily of Utrecht, Catharijnesingel 60, \\ 3511 GH Utrecht, The Netherlands; and †Department of Organic Chemistry, \\ University of Twente, PO Box 217, 7500 AE Enschede, The Netherlands
}

Received June 9, 1989, and in revised form October 6, 1989

\begin{abstract}
The reduction of a series of 2,5 -bis(1-aziridinyl)-1,4benzoquinone (BABQ) derivatives with various 3,6 substituents by the enzyme xanthine oxidase has been studied. The reduction rate has been assayed by measuring the rate of reduction of cytochrome $c$, which is very efficiently reduced by reduced BABQ species. Under nitrogen, the reduction rate correlated with the quinone reduction potential and steric parameters. Comparing reduction rates under nitrogen and air demonstrates that at BABQ concentrations $>25 \mu \mathrm{M}$ the competition for electrons from xanthine oxidase between oxygen and the BABQ derivative is dominated by the latter. This is also confirmed by the effect of superoxide dismutase (SOD): in the presence of a BABQ derivative, cytochrome $c$ reduction can be totally inhibited by SOD, although the required amount of SOD depends on the redox potential of the quinones. This indicates that SOD causes the equilibrium between semiquinone and superoxide to shift, resulting in a decrease of the semiquinone concentration. It is concluded that reduction by xanthine oxidase is a simple and effective method for reducing aziridinylbenzoquinones. (c) 1990 Academic Press, Inc.
\end{abstract}

Many important drugs used in anticancer therapy contain a quinone moiety. Mitomycin $\mathrm{C}$ and bis(1aziridinyl)benzoquinone derivatives, such as diaziquone $(\mathrm{AZQ}),{ }^{2}$ are reductively activated alkylating drugs

\footnotetext{
${ }^{1}$ To whom correspondence should be addressed.

${ }^{2}$ Abbreviations used: BABQ, 2,5-bis(1-aziridinyl)-1,4-benzoquinone; SOD, superoxide dismutase; EDTA, ethylenediamine tetraacetic acid; 1,4-BQ, 1,4-benzoquinone; $\mathrm{AZQ}$, diaziquone; DMF, $N, N$-dimethylformamide.
}

containing a quinone moiety $(1,2)$. Based on AZQ and related compounds (3) we synthesized and studied the DNA alkylating properties of a series of bis(1-aziridinyl) benzoquinones (4).

Quinone-containing compounds can be reduced in two successive one-electron steps. Reoxidation of a reduced quinone species can yield superoxide anion and other related reactive oxygen species (redox cycling) (5). Production of reduced oxygen species can be regarded as an unwanted side effect of reductively activated alkylating drugs.

In our previous studies $(4,6)$ we used $\mathrm{NaBH}_{4}$ and electrochemical reduction to activate the quinones. However, to study redoxcycling, enzymatic reduction is preferred, to let the quinones undergo multiple reductionreoxidation cycles in the presence of oxygen.

In this paper we report on the use of xanthinc oxidase for reductive activation of aziridinylbenzoquinones, using xanthine as an electron donor. Xanthine oxidase is frequently used as a source of superoxide radicals $(7,8)$. However, quinones are reported to be excellent electron acceptors from xanthine oxidase (9). Under physiological circumstances, xanthine oxidase appears to function as a NAD-dependent dehydrogenase, but during isolation it becomes an $\mathrm{O}_{2}$-utilizing oxidase, capable of reducing a wide range of substrates (9). Xanthine oxidase is found in mammalian liver microsomes (10) and is likely to be active in tumor cells (11). Xanthine oxidase is also one of the reductive enzymes found in nuclei (12), at the site where damage to nuclear DNA may occur (13).

An important point of concern in using xanthine oxidase as an activating enzyme for quinones is the possibility of simultaneous reduction of molecular oxygen (leading to superoxide) and reduction of quinone derivatives by the enzyme. 
TABLE I

General Structure of 2,5-bis(1-aziridinyl)-1,4-Benzoquinone and Structures of Derivatives

\begin{tabular}{|c|c|c|}
\hline $\mathrm{BABQ}$ derivative & $\mathrm{R}_{1}$ & $\mathrm{R}_{2}$ \\
\hline TW19 & $\mathrm{F}$ & $\mathbf{F}$ \\
\hline TW13 & $\mathrm{H}$ & $\mathrm{H}$ \\
\hline TW14 & $\mathrm{C} 1$ & C1 \\
\hline Diaziquone (AZQ) & $\mathrm{NHCOOC}_{2} \mathrm{H}_{5}$ & $\mathrm{NHCOOC}_{2} \mathrm{H}_{5}$ \\
\hline Carboquone & $\mathrm{CH}_{3}$ & $\mathrm{CH}\left(\mathrm{OCH}_{3}\right) \mathrm{CH}_{2} \mathrm{OCONH}_{2}$ \\
\hline TW22 & $\mathrm{Br}$ & $\mathrm{CH}_{3}$ \\
\hline TW25 & $\mathrm{Br}$ & $\mathrm{C}_{2} \mathrm{H}_{5}$ \\
\hline TW39 & $\mathrm{CH}_{3}$ & $\mathrm{CH}_{2} \mathrm{CH}_{2} \mathrm{OCONH}_{2}$ \\
\hline TW34 & $\mathrm{N}\left(\mathrm{CH}_{3}\right) \mathrm{C}_{2} \mathrm{H}_{4} \mathrm{OH}$ & $\mathrm{N}\left(\mathrm{CH}_{3}\right) \mathrm{C}_{2} \mathrm{H}_{4} \mathrm{OH}$ \\
\hline TW32 & $\mathrm{CH}_{3}$ & $\mathrm{C}_{2} \mathrm{H}_{5}$ \\
\hline
\end{tabular}

In this study, we used ferricytochrome $c$ to determine the reduction rate of a series of 2,5-bis(1-aziridinyl)-1,4benzoquinone (BABQ) derivatives by xanthine oxidase. We report a structure-activity relationship between the reduction rates of the $B A B Q$ derivatives by xanthine oxidase and electrochemical and steric parameters. By comparing cytochrome $c$ reduction under air and under nitrogen, we demonstrate that a competition exists for xanthine oxidase between molecular oxygen and BABQ derivatives: at $\mathrm{BABQ}$ concentrations $>25 \mu \mathrm{M}$ electron transfer from xanthine oxidase to oxygen is practically completely inhibited in favor of electron transfer to $\mathrm{BABQ}$. The position of the equilibrium between reduced $\mathrm{BABQ}$ and superoxide is studied with use of superoxide dismutase (SOD) and compared with the redox potentials of the $\mathrm{BABQ}$ derivatives.

\section{MAIERIALS AND MEIIHODS}

The structures of the BABQ compounds are described in Table I. TW13, TW25, TW32, and TW39 were prepared as described previously (4). TW14 (14), TW19 (15), and TW22 (16) were prepared as described in the literature. TW34 was a gift from Dr. J. S. Driscoll, Drug Research and Development Division of Cancer Treatment, National Institutes of Health, Bethesda, Maryland. Diaziquone was a gift from the Drug Synthesis and Chemistry Branch, National Cancer Institute, Maryland. Carboquone was a gift from the Chemical Research Laboratories, Sankyo Co., Ltd, Tokyo, Japan. The purity of all compounds was tested by HPLC analysis. Stock solutions of the BABQ derivatives contained $5 \mathrm{~mm} \mathrm{BABQ}$ in $N, N$-dimethylformamide (DMF) and were kept at $-20^{\circ}$ C. 1,4 Benzoquinone (1,4-BQ) was from Aldrich Europe, Beerse, Belgium.

Catalase (from beef liver, EC 1.11.1.6, $20 \mathrm{mg} \cdot \mathrm{ml}^{-1}, 65,000 \mathrm{U} \cdot \mathrm{mg}^{-1}$ ) and superoxide dismutase (from bovine erythrocytes, EC 1.15.1.1., $5000 \mathrm{U} \cdot \mathrm{mg}^{-1}$ ) were from Boehringer Mannheim $\mathrm{GmbH}$. The SOD stock solution contained $600 \mathrm{U} \mathrm{SOD} / \mathrm{ml}$. Cytochrome $c$ (Type III, from horse heart), xanthine (sodium salt), xanthine oxidase (Grade III, from buttermilk, $\mathrm{EC} 1.2 .3 .2,15.4 \mathrm{U} \cdot \mathrm{ml}^{-1}, 1.2 \mathrm{U} / \mathrm{mg}$ protein), and ethylenediamine tetraacetic acid (EDTA, disodium salt) were from Sigma Chemical Company, St. Iouis, Missouri. $\mathrm{Na}_{2} \mathrm{HPO}_{4} \cdot 2 \mathrm{H}_{2} \mathrm{O}$ and $\mathrm{KH}_{2} \mathrm{PO}_{4}$, analytical grade, were from Fluka AG, Buchs, Switzerland. $N, N$-Dimethylformamide was from Merck.

Absorbances were measured on a Perkin-Elmer Lambda 5 spectrophotometer. Polarograms were recorded in a vessel kept at $25^{\circ} \mathrm{C}$, using a PAR 310 polarographic detector (Princeton Applied Research, Princeton, NJ) and a PAR Model 174 polarographic analyzer.

Correlations were calculated using Statgraphics statistical program (Statistical Graphics Corporation/STSC Inc.). Lineweaver-Burk kinetics were calculated using a nonlinear data analysis program (Enzfitter, Elsevier Biosoft).

Measurement of cytochrome c reduction. BABQ stock solution was added to a thermostated solution at $25^{\circ} \mathrm{C}$, containing $20 \mu \mathrm{M}$ cytochrome $c, 50 \mu \mathrm{M}$ xanthine, and $100 \mu \mathrm{M}$ EDTA in $50 \mathrm{mM}$ phosphate buffer, $\mathrm{pH} 7.5$, to obtain the indicated concentrations of the BABQ derivative. For experiments under nitrogen, the solution was purged by passing nitrogen through the solution for $15 \mathrm{~min}$, which was enough to suppress the production of superoxide by xanthine oxidase. The reaction was started by adding xanthine oxidase to obtain a final concentration of $2 \mathrm{mU} / \mathrm{ml}$. After bubbling nitrogen through the solution for another $30 \mathrm{~s}$, nitrogen was passed over the solution and the increase of absorbance at $418 \mathrm{~nm}$ was recorded for $10 \mathrm{~min}$. The slope of the absorbance increase was initially linear. The concentration of reduced cytochrome $c$ was obtained using a molar absorptivity $(\epsilon)$ of 70,000 liter $\cdot \mathrm{mol}^{-1} \cdot \mathrm{cm}^{-1}$ at $418 \mathrm{~nm}(17)$.

For experiments under air the same procedure was followed, omitting the flushing with nitrogen.

Measurement of xanthine oxidation. To estimate the efficiency of the electron transport from xanthine via the reduced $B A B Q$ derivative to cytochrome $c$, the oxidation of xanthine was followed spectrophotometrically. However, uv absorption of oxidized and reduced BABQ species heavily influenced these measurements. Therefore, only xanthine oxidation in the presence of TW19, the BABQ derivative with the most positive redox potential, was measured. With this compound, measurements were performed at $291 \mathrm{~nm}$, which is the isoabsorptive point of the oxidized and reduced form of 'TW19. The difference in molar absorptivity between xanthine and uric acid was found to be 10,500 liter $\cdot \mathrm{mol}^{-1} \cdot \mathrm{cm}^{-1}$ at $291 \mathrm{~nm}$.

Effect of $S O D$ on cytochrome c reduction rate. To the solution, as described under Measurement of cytochrome $c$ reduction, SOD stock solution was added to the indicated concentrations. The cytochrome $c$ reduction rate is expressed as the percentage of the reduction rate in the absence of SOD.

Polarographic measurements. Polarograms were recorded from a solution containing $500 \mu \mathrm{M}$ xanthine in $50 \mathrm{mM}$ phosphate buffer, $\mathrm{pH}$ 7.5 , to which $\mathrm{BABQ}$ stock solution was added to obtain a concentration of $10 \mu \mathrm{M} B A B Q$ derivative. The solution was saturated with nitrogen by bubbling nitrogen for $15 \mathrm{~min}$. The reaction was started by adding xanthine oxidase to obtain a final concentration of $12 \mathrm{mU} / \mathrm{ml}$. After bubbling nitrogen through the solution for another $60 \mathrm{~s}$, nitrogen was passed over the solution and sampled dc polarograms were recorded at a scan rate of $5 \mathrm{mV} \cdot \mathrm{s}^{-1}$, drop time $1 \mathrm{~s}$.

\section{RESULTS \\ Reduction of Aziridinylquinones by Xanthine Oxidase under Nitrogen}

All BABQ derivatives (structures shown in Table I) were capable of reducing cytochrome $c$ under nitrogen, after reduction by xanthine oxidase. Cytochrome $c$ reduction under nitrogen in the absence of $\mathrm{BABQ}$ derivatives was low $\left(<0.02 \mu \mathrm{M} \cdot \mathrm{min}^{-1}\right)$. Addition of SOD did 


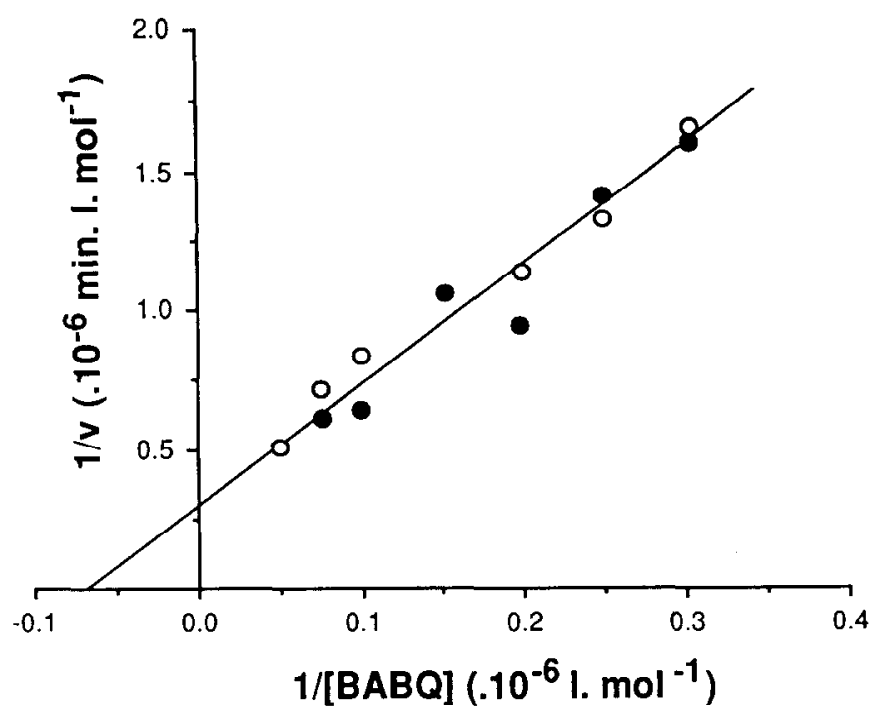

FIG. 1. Lineweaver-Burk plots of xanthine oxidation $(O)$ and cytochrome $c$ reduction $(\bullet)$ under nitrogen, in the presence of TW 19 by xanthine oxidase in a mixture containing $2 \mathrm{mU} \cdot \mathrm{ml}^{-1}$ xanthine oxidase, $50 \mu \mathrm{M}$ xanthine, and $100 \mu \mathrm{M}$ EDTA in $50 \mathrm{mM}$ phosphate buffer, pH 7.5 , at $25^{\circ} \mathrm{C}$. The samples contained $20 \mu \mathrm{M}$ cytochrome $c$. The xanthine oxidation rates are multiplied by a factor of 2 to obtain electronic equivalency of xanthine and cytochrome $c$.

not influence the cytochrome $c$ reduction rate in the presence of $\mathrm{BABQ}$ derivatives under nitrogen.

The reduction rate of cytochrome $c$ in the presence of TW19 is compared with the concomitant xanthine oxidation rate by means of a Lineweaver-Burk plot in Fig. 1. The lines are not significantly different, which indicates a very efficient electron transfer from xanthine via reduced $B A B Q$ derivative to cytochrome $c$.

The other $\mathrm{BABQ}$ compounds have more negative redox potentials than TW19 (Table II), and their semiquinone radicals, once formed by xanthine oxidase, are expected to reduce cytochrome $c$ with at least the same efficiency. Therefore, the cytochrome $c$ reduction rate under nitrogen can be taken as a direct measure for the $B A B Q$ reduction rate by xanthine oxidase.

The obtained reduction rates of a series of $\mathrm{BABQ}$ derivatives (10 $\mu \mathrm{M}$ solutions) are listed in Table II. The reduction rates of the BABQ derivatives correlated with the half-wave potentials, determined by Driebergen et al. (18) and Driebergen (19), as described by Eq. [1]:

$$
v_{\text {red }}=1.465+6.506 * E_{1 / 2}(\mathrm{~V})
$$

$n=10, r^{2}=0.71, F=19.6, p=0.002$.

The correlation coefficient is greatly improved by including a steric parameter, $M R_{\mathrm{TOT}}$, representing the sum of substituent values of molar refractivity (20):

$$
\begin{aligned}
v_{\text {red }} & =1.799+3.978 * E_{1 / 2}-0.0159 * M R_{\text {TOT }} \\
n=10, r^{2} & =0.94, F=50.0, p=0.00007 .
\end{aligned}
$$

TABLE II

Cytochrome $c$ Reduction Rates of BABQ Derivatives

\begin{tabular}{llll}
\hline BABQ derivative & $E_{1 / 2}(\mathrm{~V})$ & $M R_{\mathrm{TOT}}$ & $\begin{array}{c}v_{\text {red }}(\mathrm{CC}) \\
\left(\mu \mathrm{M} \cdot \mathrm{min}^{-1}\right)\end{array}$ \\
\hline TW19 & -0.087 & 28.9 & $0.99 \pm 0.08$ \\
TW13 & -0.105 & 29.1 & $0.99 \pm 0.08$ \\
TW14 & -0.113 & 39.1 & $0.73 \pm 0.12$ \\
AZQ & -0.149 & 69.4 & $0.028 \pm 0.015$ \\
CbQ & -0.182 & 60.7 & $0.005 \pm 0.003$ \\
TW22 & -0.185 & 41.6 & $0.49 \pm 0.04$ \\
TW25 & -0.210 & 46.2 & $0.21 \pm 0.03$ \\
TW39 & -0.213 & 53.9 & $0.007 \pm 0.002$ \\
TW34 & -0.225 & 68.8 & $0.044 \pm 0.015$ \\
TW32 & -0.227 & 43.0 & $0.12 \pm 0.02$ \\
\hline
\end{tabular}

Note. Cytochrome $c$ reduction rates of BABQ derivatives $\left(v_{\text {red }}(\mathrm{CC})\right)$ under nitrogen, in the presence of $10 \mu \mathrm{MBABQ}$ derivative, $2 \mathrm{mU} \cdot \mathrm{ml}^{-1}$ xanthine oxidase, $50 \mu \mathrm{M}$ xanthine, and $100 \mu \mathrm{M}$ EDTA in $50 \mathrm{mM}$ phosphate buffer, $\mathrm{pH} 7.5$, at $25^{\circ} \mathrm{C}$. Values for $v_{\text {red }}(\mathrm{CC})$ are means from at least five experiments. $E_{1 / 2}=$ redoxpotential, as determined by Driebergen $(18,19), M R_{\text {TOT }}=$ sum of molar refractivity values of the 2,3 , 5 , and 6 substituents.

Lineweaver-Burk plots of cytochrome $c$ reduction under nitrogen in the presence of TW19, TW22, TW25, and AZQ are shown in Fig. 2. $K_{m}$ values of TW19, TW22, and TW25 were in the same range $(11-21 \mu \mathrm{M})$; the $K_{m}$ value for $A Z Q$ was $257 \pm 91 \mu \mathrm{M}$. The maximum reduction rates obtained from this graph increased in the order $\mathrm{AZQ}\left(0.7 \pm 0.3 \mu \mathrm{M} \cdot \mathrm{min}^{-1}\right) \simeq \mathrm{TW} 25\left(0.5 \pm 0.1 \mu \mathrm{M} \cdot \mathrm{min}^{-1}\right)$ $<\mathrm{TW} 22\left(1.4 \pm 0.1 \mu \mathrm{M} \cdot \mathrm{min}^{-1}\right)<\mathrm{TW} 19(2.4 \pm 0.5 \mu \mathrm{M}$. $\left.\min ^{-1}\right)$. BABQ derivatives that slowly reduce cytochrome $c$ in the presence of xanthine oxidase also showed a slow decrease of the height of the cathodic wave in polarograms, indicating slow reduction by xan-

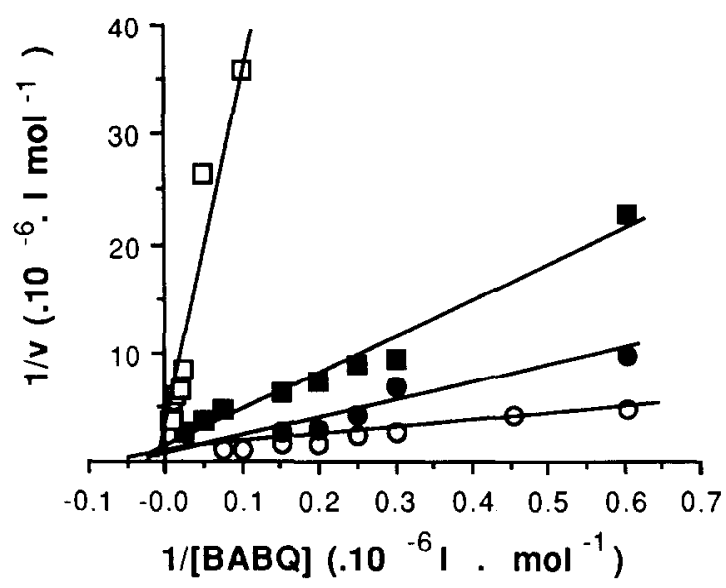

FIG. 2. Lineweaver-Burk plots of cytochrome $c$ reduction rates in

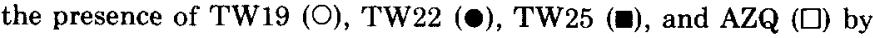
xanthine oxidase under nitrogen, in a mixture containing $2 \mathrm{mU} \cdot \mathrm{ml}^{-1}$ xanthine oxidase, $50 \mu \mathrm{M}$ xanthine, $20 \mu \mathrm{M}$ cytochrome $c$, and $100 \mu \mathrm{M}$ EDTA in $50 \mathrm{mM}$ phosphate buffer, $\mathrm{pH} 7.5$, at $25^{\circ} \mathrm{C}$. 


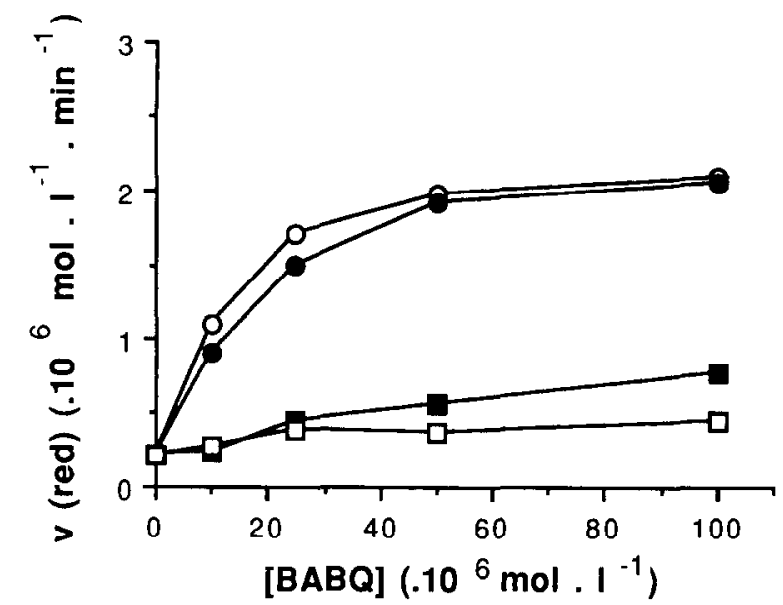

FIG. 3. Increase of the cytochrome $c$ reduction rate in the presence of TW19 (O), TW13 (๑), 'TW25 (ם), and AZQ ( $\square$ ) in an aerobic mixture at $25^{\circ} \mathrm{C}$ containing $2 \mathrm{mU} \cdot \mathrm{ml}^{-1}$ xanthine oxidase, $50 \mu \mathrm{M}$ xanthine, $20 \mu \mathrm{M}$ cytochrome $c$, and $100 \mu \mathrm{M}$ EDTA in $50 \mathrm{mM}$ phosphate buffer, pH 7.5.

thine oxidase (results not shown). The order of the compounds was the same as with the reduction rate of cytochrome $c$ (Table II). Higher concentrations of xanthine oxidase were needed in polarographic experiments than in cytochrome $c$ measurements. Adsorption or inactivation of xanthine oxidase by mercury may be the cause of this.

\section{Reduction of Aziridinylbenzoquinones by Xanthine Oxidase under Air}

To study the influence of oxygen on the cytochrome c reduction rate, experiments under air were performed with some BABQ derivatives. The results for a number of $B A B Q$ derivatives are represented in Fig. 3. The cytochrome $c$ reduction in the presence of BABQ derivatives increases markedly compared to the situation where xanthine oxidase is incubated without $\mathrm{BABQ}$ derivatives $([\mathrm{BABQ}]=0)$. The concomitant xanthine oxidation rates under air and under nitrogen were compared for the compound TW19 (Fig. 4). The xanthine oxidation rate was higher under air than under nitrogen. The maximum xanthine oxidation rates as determined from Fig. 4 did not differ significantly. Reoxidation of cytochrome $c$ by $\mathrm{H}_{2} \mathrm{O}_{2}$, formed from superoxide that did not react with cytochrome $c$, could influence the results (21). However, addition of catalase to the incubation mixture to remove hydrogen peroxide did not influence the cytochrome $c$ reduction rate during the incubation time.

\section{Effect of SOD on Cytochrome c Reduction Rate under Air}

Figure 5 shows the inhibition of the cytochrome $c$ reduction rate by SOD in the presence of a number of BABQ derivatives that differ in $E_{1 / 2}$ value (see Table II).

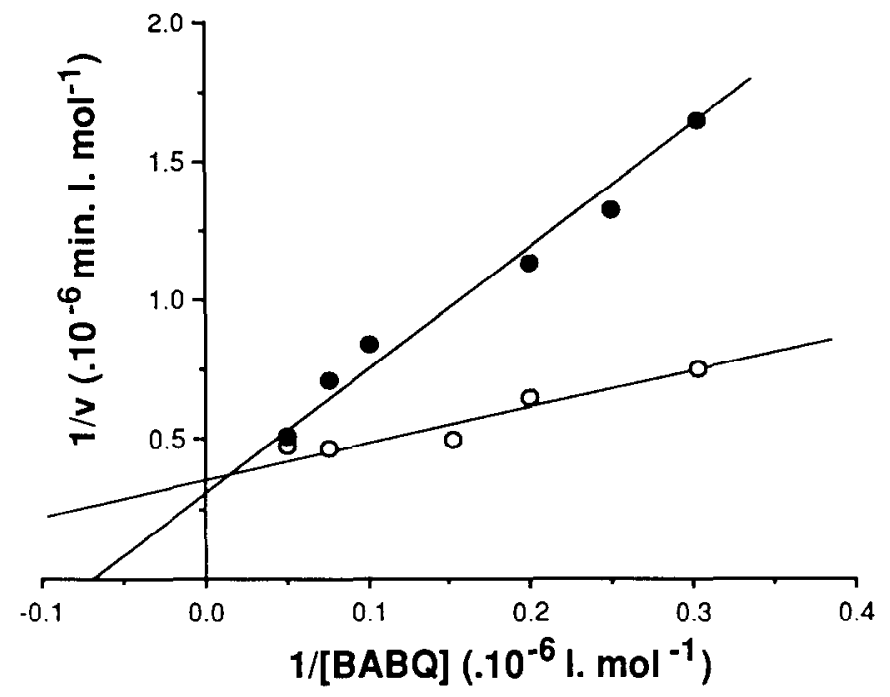

FIG. 4. Lineweaver-Burk plots of xanthine oxidation in the presence of TW19 in a mixture containing $2 \mathrm{mU} \cdot \mathrm{ml}^{-1}$ xanthine oxidase, $50 \mu \mathrm{M}$ xanthine, $20 \mu \mathrm{M}$ cytochrome $c$, and $100 \mu \mathrm{M}$ EDTA in $50 \mathrm{mM}$ phosphate buffer, $\mathrm{pH} 7.5$, at $25^{\circ} \mathrm{C}$, under air $(O)$ or nitrogen $(\bullet)$. Observations were made at $291 \mathrm{~nm}$, the isosbestic point of reduced/unreduced TW19. Xanthine oxidation rates are represented as described in the legend to Fig. 1.

The inhibition by SOD is plotted as percentage of the reduction rate in the absence of SOD. 1,4-Benzoquinone was included because of its positive redox potential.

The cytochrome $c$ reduction under air in the presence of $10 \mu \mathrm{M} \mathrm{BABQ}$ derivative could be inhibited completely by addition of SOD. Concentrations of SOD needed to reduce the cytochrome $c$ reduction rate with $50 \%$ ([SOD $]_{50 \%}$ ) were obtained from these curves (Table III).

\section{DISCUSSION}

BABQ derivatives, when reduced by xanthine oxidase, are capable of reducing cytochrome $c$ with a high effi-

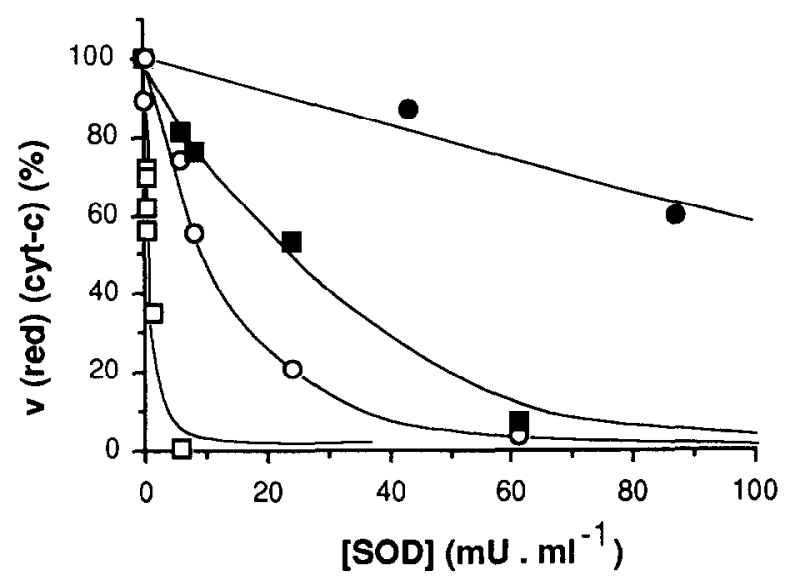

FIG. 5. Inhibition of cytochrome $c$ reduction by superoxide dismutase in an aerobic mixture containing $2 \mathrm{mU} \cdot \mathrm{ml}^{-1}$ xanthine oxidase, 50 $\mu \mathrm{M}$ xanthine, $20 \mu \mathrm{M}$ cytochrome $c, 10 \mu \mathrm{M}$ BABQ derivative, and 100 $\mu \mathrm{M}$ EDTA in $50 \mathrm{mM}$ phosphate buffer, $\mathrm{pH} 7.5$, at $25^{\circ} \mathrm{C}$. (•) 1,4-benzoquinone, (O) TW13, (匹) TW22, ( $\square$ ) TW39. 
TABLE III

Concentrations of SOD Causing a 50\% Decrease in Cytochrome $c$ Reduction Rate

\begin{tabular}{lccl}
\hline BABQ derivative & {$\left[\mathrm{SOD}_{50 \%}\right]\left(\mathrm{mU} \cdot \mathrm{ml}^{-1}\right)$} & $E_{1 / 2}(\mathrm{~V})(19)$ & \multicolumn{1}{c}{$K$} \\
\hline 1,4-BQ & 117 & +0.055 & 0.000231 \\
TW13 & 13 & -0.105 & 0.117 \\
TW22 & 25 & -0.185 & 2.65 \\
TW39 & 0.94 & -0.213 & 7.88 \\
None & 0.46 & - & - \\
\hline
\end{tabular}

Note. Concentrations of SOD causing a $50 \%$ decrease in cytochrome $c$ reduction rate, in a mixture containing $10 \mu \mathrm{M}$ BABQ derivative, 2 $\mathrm{mU} \cdot \mathrm{ml}^{-1}$ xanthine oxidase, $50 \mu \mathrm{M}$ xanthine, $100 \mu \mathrm{M}$ EDTA, and $20 \mu \mathrm{M}$ cytochrome $c$ in $50 \mathrm{~mm}$ phosphate buffer, $\mathrm{pH} 7.5 . \mathrm{K}$ is the equilibrium constant of Eq. [4], computed with Fq. [5]

ciency. The BABQ derivative TW19 investigated in this study reduced cytochrome $c$ practically quantitatively after reduction by xanthine oxidase (Fig. 1). The other compounds have lower redox potentials and are expected to react with at least the same efficiency.

To test whether differences in cytochrome $c$ reduction rates under nitrogen were really due to differences in reduction rate by xanthine oxidase, or to differences in reactivity of reduced $\mathrm{BABQ}$ species with cytochrome $c$, reduction of $\mathrm{BABQ}$ derivatives was followed by polarography. The results confirmed that the order of the $\mathrm{BABQ}$ derivatives with regard to cytochrome $c$ reduction rate represented the order of $B A B Q$ reduction by xanthine oxidase.

The cytochrome $c$ reduction rate under nitrogen was taken as a measure for the reduction rate of $B A B Q$ derivatives by xanthine oxidase. The correlation of the BABQ reduction rate with the redox potential and the steric parameter $M R_{\text {тот }}$ (Eq. [2]) indicates that next to redox properties of the quinones, steric factors are also important in enzymatic reductive activation. The $K_{m}$ values, determined from Fig. 2, increase with $M R_{\text {TOT }}$, indicating decreased affinity for xanthine oxidase when larger substituents are present. In tumor cells quinones are likely to be activated by xanthine oxidase and similarly acting enzymes (11), but other reductive enzymes are present and likely to be involved in quinone reduction, especially NADPH-dependent cytochrome $\mathrm{P} 450$ reductase (22). The finding that with xanthine oxidase, aziridinylbenzoquinone compounds with small substituents are more efficiently reduced is, however, interesting from the viewpoint of drug design, because in an earlier study we observed that aziridinylbenzoquinone derivatives with small substituents alkylate DNA more efficiently than derivatives with large substituents (4).

When we compare the reduction rates of the $\mathrm{BABQ}$ derivatives under nitrogen and under air, some conclusions can be drawn. At a low concentration of BABQ derivative (Fig. 4), cytochrome $c$ reduction under air is higher than under nitrogen. This indicates that under these conditions considerable direct oxygen reduction by xanthine oxidase takes place. At a high concentration of BABQ derivative, the cytochrome $c$ reduction rates under nitrogen and air become identical. This means, that at higher BABQ concentrations ( $>25 \mu \mathrm{M})$, cytochrome $c$ reduction under air is mainly caused by reduced $B A B Q$ species, and (in the presence of cytochrome $c$ ) no substantial direct oxygen reduction occurs.

Xanthine oxidase has been reported to catalyze oneelectron reduction of daunomycin and related compounds $(23,24,25)$, leading to semiquinone and superoxide production. A combination of one- and two-electron reduction has also been reported (26). The question, whether reductive activation is exclusively one-electron or mixed, is probably of minor importance in predicting semiquinone-mediated superoxide production, because semiquinone radicals are known to exist in a dismutation equilibrium (Eq. [3]), in which the semiquinone $\left(Q^{-}\right)$is in equilibrium with the two-electron reduced quinone $\left(Q^{2-}\right)$ and the oxidized quinone $(Q)$ :

$$
2 \mathbf{Q}^{-} \rightleftarrows \mathrm{Q}^{2-}+\mathrm{Q}
$$

This equilibrium can be assumed to be efficiently reached with typical rate constants of $10^{7}-10^{9} \mathrm{M}^{-1} \cdot \mathrm{s}^{-1}$ (27). The one-electron reduced semiquinone is in redox equilibrium with superoxide (Eq. [4]):

$$
\mathrm{Q}^{-}+\mathrm{O}_{2} \rightleftarrows \mathrm{O}_{\dot{2}}^{-}+\mathrm{Q}
$$

The position of the redox equilibrium (Eq. [4]) is dependent on the difference between the redox potential of the $\mathrm{BABQ}$ derivative and the redox potential of the $\mathrm{O}_{2} / \mathrm{O}_{2}^{-}$couple $(-0.16 \mathrm{~V}$, Ref. (28)) and is given by the equilibrium constant $K(29)$ :

$$
K=\frac{\left[\mathrm{O}_{\overline{2}}^{-}\right][\mathrm{BABQ}]}{\left[\mathrm{O}_{2}\right][\mathrm{BABQ} \cdot]}=e^{38.94\left(-0.16-E_{1 / 2}\right)}
$$

For $\mathrm{BABQ}$ derivatives having a more positive redox potential (BABQ/BABQ.) than the oxygen/superoxide couple, the equilibrium is on the side of semiquinone. $K$ values were computed using Eq. [5] (Table III). Halfwave potentials in Tables II and III are determined as two-electron reduction potentials (18), whereas oneelectron reduction potentials are relevant in Eqs. [4] and [5]. In water, however, the difference between these values is small $(30,31)$.

Addition of SOD will lead to a decrease in superoxide concentration, by enhancement of the dismutation rate of superoxide. As a result, Eq. [4] will shift to the side of $\mathrm{O}_{\overline{2}}^{-}$and the concentration of $\mathrm{BABQ}^{-}$will decrease. The cytochrome $c$ reduction rate, which is dependent on 


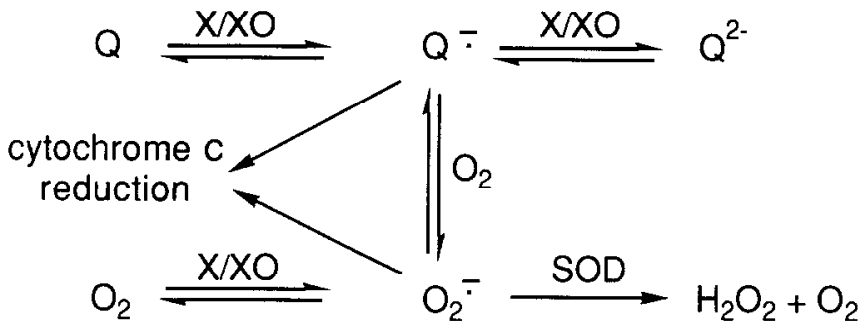

FIG. 6. Routes of electron transport from xanthine oxidase to cytochrome $c$ in the presence of a BABQ derivative and oxygen. $\mathrm{X}$, xanthine; $\mathrm{XO}$, xanthine oxidase; $\mathrm{Q}, \mathrm{Q}^{-}$, and $\mathrm{Q}^{2-}$ are the oxidized and the one- and two-electron reduced BABQ species, respectively.

both $\mathrm{O}_{\overline{2}}^{-}$and $\mathrm{BABQ}^{-}$will decrease (see Fig. 6). In our experiments, we observe that higher amounts of SOD are needed to inhibit cytochrome $c$ reduction when $B A B Q$ derivatives are present than without $B A B Q$. The amount of SOD needed for inhibition of cytochrome $c$ reduction increases when the reduction potential of the BABQ derivative is more positive, and the $K$-value (Eq. [4]) is smaller (Table III). This indicates, even though one has to take into account that $\mathrm{BABQ}$ derivatives react more efficiently with cylochrome $c$ than superoxide, that the greatest part of the reducing equivalents from xanthine go to $\mathrm{BABQ}^{-}$, especially when the redox potential of $\mathrm{BABQ}$ is more positive. This is explained both by the high reduction rate of the $B A B Q$ derivatives and by the position of the equilibrium (Eq. [4]).

A similar explanation for the effect of SOD on cytochrome $c$ reduction was provided by Winterbourn (32), who studied this effect with a series of methyl-substituted and sulfonated quinone derivatives.

In summary, we conclude that aziridinylbenzoquinones are efficient electron acceptors from xanthine oxidase. The rate of reduction of these compounds by xanthine oxidase depends on the redox potential and the size of the molecule. At quinone concentrations $>25 \mu \mathrm{M}$ quinone reduction by xanthine oxidase prevails over oxygen reduction. Therefore, reduction by xanthine oxidase is an efficient and simple method to study formation of reactive oxygen intermediates formed by reduced aziridinylbenzoquinones. Measurement of the part of the cytochrome $c$ reduction rate under air that is inhibited by SOD does not reflect the production of superoxide. We fully subscribe to the warning of Winterbourn (32), that SOD effects, when used to demonstrate the involvement of superoxide, should be interpreted with caution. The results of this study will be used to investigate the formation of reactive oxygen intermediates and DNA damage by reduced $B A B Q$ derivatives.

\section{REFERENCES}

1. Sartorelli, A. C. (1986) Biochem. Pharmacol. 35, 67-69.

2. Gutierrez, P. L., Biswal, S., Nardino, R., and Biswal, N. (1986) $J$. Cancer Res. 46, 5779-5785.
3. Driscoll, J. S. (1983) in Structure-Activity Relationships of Antitumour Agents (Reinhoudt, D. N., Connors, T. A., Pinedo, H. M., and Van de Pol, K. W., Eds.), Martinus Nijhoff, Den Haag.

4. Lusthof, K. J., Groothuis-Pielage, I. L., Decuyper, J., de Mol, N. J., Janssen, L. H. M., Verboom, W., and Reinhoudt, D. N. (1988) Anti-Cancer Drug Design 3, 147-155.

5. Kappus, H. (1986) J. Biochem. Pharmacol. 35, 1-6.

6. Lusthof, K. J., de Mol, N. J., Janssen, L. H. M., Verboom, W., and Reinhoudt, D. N. (1989) Chem. Biol. Interact. 70, 249-262.

7. Misra, H. P., and Fridovich, I. (1972) J. Biol. Chem. 247, 188192.

8. Link, E. M., and Riley, P. A. (1988) Biochem. J. 249, 391-399.

9. Rajagopalan, K. V. (1980) in The Enzymatic Basis of Detoxication (Jakoby, W. B., Ed.), Vol. I., pp. 295-309, Academic Press, New York.

10. Beaune, P. H., and Guengerich, F. P. (1988) Pharmacol. Ther. 37, 193-211.

11. Schwartz, H. S. in Molecular Aspects of Anti-cancer Drug Action (Neidle, S., and Waring, M. J., Eds.), pp. 93-125, Verlag Chemie, Weinheim.

12. Hashimoto, S. (1974) Agric. Biol. Chem. 38, 1697-1702.

13. Bachur, N. R., Gee, M. V., and Friedman, R. D. (1982) Cancer Res. 42, 1078-1081.

14. British Patent 762723 Furb. Fub. Bayer A. G. (1956); Chem. Abstr. (1957) 51, 12153h.

15. Chou, F., Khan, A. H., and Driscoll, J. S. (1976) J. Med Chem 19, 1302-1308.

16. Nakao, H., Arakawa, M., Nakamura, T., and Fukushima, M. (1972) Chem. Pharm. Bull. 20, 1968-1979.

17. Fridovich, I. (1986) In Adv. Enzymol. (Meister, A., Ed.), Vol. 58, pp. 61-97, John Wiley \& Sons, New York.

18. Driebergen, R. J., Holthuis, J. J. M., Hulshoff, A., Postma-Kelder, S. J., Verboom, W., Reinhoudt, D. N., and Lelieveld, P. (1986) Anticancer Res. 6, 605-620.

19. Driebergen, R. J. (1987) Qualitative and Quantitative Aspects of Structure-Electrochemistry-Cytotoxicity Relationships of Aziridinylquinones. Ph.D. thesis, Utrecht.

20. Hansch, C., and Leo, A., Eds. (1979) Substituent Constants for Correlation Analysis in Chemistry and Biology, Wiley, New York.

21. VandeWalle, P. L., and Petersen, N. O. (1987) FEBS Lett. 210, 195-198.

22. Powis, G. (1987) Pharmacol. Ther, 35, 57-162.

23. Komiyama, T., Kikuchi, T., and Sugiura, Y. (1986) J. Pharmacobio-Dyn. 9, 651-664.

24. Pan, S. S., and Bachur, N. R. (1979) J. Mol. Pharmacol. 17, 9599.

25. Schreiber, J., Mottley, C., Sinha, B. K., Kalyanaraman, B., and Mason, R. P. (1987) J. Amer. Chem. Soc. 109, 348-351.

26. Nakamura, M., and Yamazaki, I. (1973) Biochim. Biophys. Acta 327, 247-256.

27. Butler, J., and Hoey, B. M. (1987) Brit. J. Cancer 55, Suppl. VIII, 53-59.

28. Wood, P. M. (1987) TIBS 12, 250-251.

29. Skoog, D. A., and West, D. M. (1976) Fundamentals of Analytical Chemistry, third ed., Holt, Rinehart \& Winston, New York.

30. Suga, K., and Aoyagui, S. (1986) Bull. Chem. Soc. Japan. 59, 1937-1939.

31. Prince, R. C., Lloyd-Williams, P., Bruce, J. M., and Dutton, P. L. (1986) in Methods in Enzymology (Fleischer, S., and Fleischer, B., Eds.), Vol. 125, pp. 109-119, Academic Press, San Diego.

32. Winterbourn, C. C. (1981) Arch. Biochem. Biophys. 209, 159-167. 